\title{
The occurrence of permanent thyroid failure in patients with subclinical postpartum thyroiditis
}

\author{
F Azizi \\ Endocrine Research Center, Shaheed Beheshti University of Medical Sciences, P O Box 19395-4763, Tehran, Islamic Republic of Iran \\ (Correspondence should be addressed to F Azizi; Email: Azizi@erc.ac.ir)
}

\begin{abstract}
Objective: The long-term effect of the subclinical form of postpartum thyroid dysfunction (PPTD) has not been well established. This study was conducted to evaluate the outcome of permanent hypothyroidism in a large cohort of women with PPTD.

Design and methods: Of 213 women with PPTD, 172 (81\%) returned for follow-up. There were 27 $(16 \%)$ with subclinical (group 1) and 145 (84\%) with overt hypothyroidism (group 2). They were all treated with levothyroxine for $23 \pm 16$ months and followed-up for thyroid function after thyroxine $\left(\mathrm{T}_{4}\right)$ withdrawal.

Results: In group 1, the time of occurrence of PPTD was longer, serum $\mathrm{T}_{4}$ was higher and TSH was lower than in group 2 . After $\mathrm{T}_{4}$ withdrawal, 59 and $64 \%$ of patients became hypothyroid in groups 1 and 2 respectively; however, serum TSH was increased in group 2 as compared with group 1 $(29.7 \pm 8.4$ vs $16.4 \pm 15.4 \mathrm{mU} / \mathrm{l}, P<0.002)$. The duration of euthyroidism, serum free $\mathrm{T}_{4}$ and triiodothyronine indices and thyroperoxidase antibodies were not significantly different between the two groups.

Conclusion: It was concluded that a high percentage of patients with the subclinical form of PPTD proceed to permanent thyroid failure. The timely recognition of mild to severe cases of PPTD is important for the improvement of life for mothers and infants.
\end{abstract}

European Journal of Endocrinology 153 367-371

\section{Introduction}

Postpartum thyroid dysfunction (PPTD), a syndrome of thyroid dysfunction that has been reviewed extensively, occurs in the first year after parturition (1-3). It consists of a group of autoimmune disorders, characterized by postpartum development of transient hyperthyroidism, hypothyroidism or both (4). Depending on differences in ethnic groups, geographical locations, methodology, or the rate of follow-up visits for patients in the first year after parturition, a wide range of prevalence of PPTD ranging from 1.1 to $11.4 \%$ has been reported (4-11).

A significant number of patients with positive PPTD having the hypothyroid form of the illness develop permanent hypothyroidism $(12,13)$. It has been shown that multiparity, previous history of spontaneous abortion, age and some immunogenetic factors including Human Leukocyte Antigen (HLA)-DRW9, HLA-B51 and anti-thyroid antibodies may be related to the development of permanent hypothyroidism (13-16).

In one epidemiologic study, only $48 \%$ of patients had moderate to severe symptoms and signs of hypothyroidism requiring maintenance doses of levothyroxine
$\left(\mathrm{L}^{-} \mathrm{T}_{4}\right)(11)$. Many cases of PPTD may therefore be subclinical and escape recognition during the acute postpartum phase. Since there is a paucity of information regarding the long-term effect of subclinical PPTD, this study aimed at evaluating the characteristics of PPTD and the outcome of permanent hypothyroidism in women with subclinical hypothyroidism in the postpartum period and comparing their findings with those in women with overt postpartum hypothyroidism.

\section{Materials and methods}

\section{Study population}

Two hundred and thirteen women with diagnoses of PPTD presenting as hypothyroid were enrolled in this cohort study. Excluding criteria were past history of thyroid dysfunction, including hypothyrodism (except PPTD), Graves' disease, and radioiodine and surgical treatment. All patients were 3 to 10 months postpartum and had at least one of the following symptoms: growth of the thyroid, lethargy, fatigue, depression, cold intolerance, dry skin, weight gain, constipation and sleepiness; $52 \%$ were referred by gynecologists, 
pediatricians or internists and $48 \%$ came directly to the endocrine clinic; $42 \%$ complained of an enlargement in the thyroid region and $19 \%$ had suffered an episode of transient thyrotoxicosis 2-4 months after delivery.

A physical examination was performed on each patient. Thyroid weight was estimated and goiter was classified according to WHO criteria (17). Thyroidal radioiodine uptake was carried out in those who were not breast feeding. Ultrasonographic evaluation of the thyroid and serum determination of thyroxine $\left(\mathrm{T}_{4}\right)$, tri-iodothyronine $\left(\mathrm{T}_{3}\right)$, resine $\mathrm{T} 3$ uptake $\left(\mathrm{RT}_{3} \mathrm{U}\right)$, thyrotropin (TSH) and anti-thyroglobulin and thyroperoxidase antibodies (anti-Tg and TPOAb) were carried out.

\section{Follow-up visits}

All patients required treatment because of goiter and/or symptoms, and all were therefore treated with $\mathrm{L}_{-} \mathrm{T}_{4}$ (Levothyroxine, Iran Hormone, Tehran, Iran). An endocrinologist saw each patient every 3-6 months and the dose of $\mathrm{L}-\mathrm{T}_{4}$ was adjusted to maintain serum TSH levels between 0.3 and $3.0 \mathrm{mU} / \mathrm{l}$. After $12-24$ months of therapy, patients were advised to discontinue $\mathrm{T}_{4}$ therapy and to return in 1 month. Follow-up visits were scheduled every month for the first 6 months and then at 9, 12, 18, 24, 36, 48 months and yearly thereafter, until hypothyroidism occurred. The patient was advised to return to the clinic in between visits whenever she experienced symptoms of hypothyroidism. At each visit, a $10 \mathrm{ml}$ blood sample was obtained for the measurements of $\mathrm{T}_{4}, \mathrm{~T}_{3}, \mathrm{RT}_{3} \mathrm{U}$ and $\mathrm{TSH}$.

\section{Measurements}

Hormone assays Serum concentrations of $\mathrm{T}_{4}$ and $\mathrm{T}_{3}$ by RIA, TSH by IRMA and an $\mathrm{RT}_{3} \mathrm{U}$ test were performed using commercial kits from Orion Diagnostica, Fenzia, Finland. The free $\mathrm{T}_{4}$ index and free $\mathrm{T}_{3}$ index were then calculated. In all assays, the inter- and intra-assay coefficients of variation were below 11 and $9 \%$ respectively. Reference ranges for euthyroid subjects were: $\mathrm{T}_{4}, 4.5-$ $12.5 \mu \mathrm{g} / \mathrm{dl} ; \mathrm{T}_{3}, 70-200 \mathrm{ng} / \mathrm{dl}$; TSH, $0.2-5.9 \mathrm{mU} / \mathrm{l}$; $\mathrm{RT}_{3} \mathrm{U}, 25-35 \%$; free $\mathrm{T}_{4}$ index, 4.5-12.5; and free $\mathrm{T}_{3}$ index, 70-200.

Thyroid antibodies TPOAb titers were measured, using ELISA kits from Radim, Pomezia, Italy. Values above $100 \mathrm{IU} / \mathrm{ml}$ were considered positive. The interand intra-assay coefficients of variation were 7.2 and $6.5 \%$ respectively.

\section{Methods of analysis}

On the basis of the results of serum hormone concentrations determined, patients were divided into two groups: (group 1) subclinical hypothyroid (TSH $>5.0 \mathrm{mU} / \mathrm{l}$ and $\mathrm{T}_{4} \geq 4.5 \mu \mathrm{g} / \mathrm{dl}$ ) and (group 2) overt hypothyroid ( $\mathrm{TSH}>5.0 \mathrm{mU} / \mathrm{l}$ and $\mathrm{T}_{4}<4.5 \mu \mathrm{g} / \mathrm{dl}$ ).
Descriptive statistical descriptions such as mean, median, range, standard deviation and proportions were used. The normality of variables was tested using the one-sample Kolmogorov-Smirnov test. Since some variables did not meet the criteria of normality, their natural logarithm was taken prior to analysis. Differences between mean values for quantitative variables were evaluated using Student's t-test. Chi square and Mann-Whitney tests were used for analysis of nominal and ordinal variables. The log rank test was employed for difference in cumulative recurrence of hypothyroidism between groups. To assess the relation between serum TSH and other factors, multiple stepwise regressions were employed. All $P$ values were obtained from two-tailed tests, and only values below 0.05 were considered significant. The conversion ratios for $\mathrm{T}_{4}$ and $\mathrm{T}_{3}$ from $\mu \mathrm{g} / \mathrm{dl}$ and $\mathrm{ng} / \mathrm{dl}$ to $\mathrm{nmol} / \mathrm{l}$ are 12.87 and 0.01536 respectively. The Research Ethics Committee of the Shaheed Beheshti University of Medical Sciences approved this study.

\section{Results}

One hundred and seventy-two (81\%) of the 213 women who developed PPTD returned for the followup study. In the past, $32(15 \%)$ had given a history of PPT after their previous pregnancy, $2-6$ years prior to the current one.

There was no significant difference in age, time of occurrence of symptoms, severity of hypothyroidism and serum $\mathrm{T}_{4}, \mathrm{~T}_{3}$, TSH and TPOAb levels between the 19 patients who did not return for follow-up and the other women.

\section{Features of postpartum hypothyroidism}

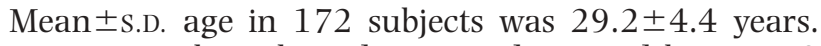
Postpartum hypothyroidism was diagnosed between 3 and 10 months after delivery with a mean \pm S.D. of $5.8 \pm 1.9$ months. In their physical examinations all patients had a palpable goiter, and $46 \%$ had visible enlargement of the thyroid gland (grade 2). Ultrasonographic evaluation detected diffuse or multifocal hypoechogenity in $93 \%$ of patients. Radioiodine uptake of the thyroid was measured in $52(30 \%)$ patients who were not breast feeding. In all patients, 24-h radioiodine uptake was below 7\%. Positive titer of anti-thyroid antibody was found in 158 (92\%) patients: 94 demonstrated both TPOAb and anti-Tg, 43 only TPOAb and 22 only anti-Tg elevation.

There were $27(16 \%)$ and $145(84 \%)$ patients in the subclinical and overt hypothyroidism groups respectively. Clinical and laboratory findings of the two groups are presented in Table 1. Time of occurrence of PPTD after delivery was longer, serum $\mathrm{T}_{4}$ was higher and serum TSH was decreased in group 1 as compared with group 2. 
Table 1 Clinical and laboratory findings in 172 patients at the time of postpartum thyroiditis-induced hypothyroidism. Values are means \pm S.D.

\begin{tabular}{lccc}
\hline & $\begin{array}{c}\text { Group 1 } \\
\text { (subclinical) } \\
(n=27)\end{array}$ & $\begin{array}{c}\text { Group 2 } \\
\text { (overt) } \\
(n=145)\end{array}$ & $\boldsymbol{P}$ \\
\hline Age (years) & $29.1 \pm 3.7$ & $29.3 \pm 4.7$ & $\mathrm{NS}$ \\
Time after delivery (months) & $6.4 \pm 2.3$ & $5.7 \pm 1.5$ & 0.001 \\
Estimated size of goiter $(\mathrm{g})$ & $31.5 \pm 5.6$ & $30.6 \pm 6.9$ & $\mathrm{NS}$ \\
Free $\mathrm{T}_{4}$ index & $4.9 \pm 0.3$ & $2.2 \pm 0.9$ & 0.001 \\
Free $\mathrm{T}_{3}$ index & $110 \pm 23$ & $71 \pm 21$ & $\mathrm{NS}$ \\
Serum TSH (mU/l) & $28 \pm 16$ & $64 \pm 26$ & 0.005 \\
\hline
\end{tabular}

NS, not significant.

\section{Duration of $T_{4}$ treatment}

In 172 PPTD patients, the duration of $\mathrm{T}_{4}$ treatment was $12-24,25-30,30-36$ and 36-84 months in 65,13 , 10 and $12 \%$ respectively. Duration of therapy beyond 24 months was due to patient preference or delays in clinic visits. Duration of $\mathrm{T}_{4}$ treatment was $23.7 \pm 12.4$ and $23.3 \pm 16.9$ months in groups 1 and 2 respectively.

\section{Thyroid function at follow-up}

The median (range) of follow-up from the time of $\mathrm{T}_{4}$ withdrawal until the occurrence of hypothyroidism or until the end of the study was 16 19 (1-120) months. Table 2 shows the outcome of thyroid function in the patients studied. Of 172 patients, 64 (37\%), 52 (30\%) and 56 (33\%) were euthyroid, subclinical and overt hypothyroid respectively. There were more subclinical and overt hypothyroid patients in groups 1 and 2 respectively, but the difference was not statistically significant. Serum TSH was decreased in group 1 as compared with group $2(16.4 \pm 15.4$ vs $29.7 \pm 28.4 \mathrm{mU} / \mathrm{l}$ respectively, $P<0.002)$. There was no significant difference in duration of euthyroidism after $\mathrm{T}_{4}$ withdrawal, and $\mathrm{T}_{4}, \mathrm{~T}_{3}$ and anti-TPOAb titers between the two groups.

\section{Presentation and outcome in the subclinical group}

All patients in this group had free $\mathrm{T}_{4}$ index $\geq 4.5$ at presentation with free $\mathrm{T}_{3}$ index and TSH ranging between 80 and 160 and 11 and $90 \mathrm{mU} / \mathrm{l}$ respectively. Serum TSH was between 11 and 20 in nine, between 21 and 50 in sixteen and $>50 \mathrm{mU} / \mathrm{l}$ in one patient.

Hypothyroidism occurred 1-36 months after $\mathrm{T}_{4}$ withdrawal with a mean of $11.4 \pm 9.5$ (median 5) months. The duration of follow-up in those who remained euthyroid was $14.4 \pm 8.1$ months and the duration of euthyroidism was $9.5 \pm 10.1$ months in those patients who became hypothyroid. There was no difference in age, time or thyroid function tests of the original presentation of postpartum hypothyroidism between those who remained euthyroid and patients who became hypothyroid after $\mathrm{L}_{-} \mathrm{T}_{4}$ withdrawal.

Rates of recurrence of hypothyroidism after $\mathrm{L}^{-\mathrm{T}_{4}}$ withdrawal are shown in Fig. 1. Although hypothyroidism occurred more frequently in group 2 in the first few months after discontinuation of $\mathrm{L}-\mathrm{T}_{4}$ therapy, the difference between the two groups was significant only at 2 months after $\mathrm{L}_{-} \mathrm{T}_{4}$ withdrawal (Fig. 1).

Ultimately 16 of 27 patients in the subclinical group were hypothyroid. The percentage rate of the development of permanent hypothyroidism was $37,44,52$ and $59 \%$ after $6,12,24$ and 36 months respectively. Mean serum TPOAb concentrations were $389 \pm 312$ and $315 \pm 298 \mathrm{IU} / \mathrm{ml}$ in hypo- and euthyroid patients respectively. The difference was not significant between the two groups.

\section{Discussion}

This study demonstrated that more than half of the women with subclinical postpartum hypothyroidism developed recurrent thyroid failure after $\mathrm{T}_{4}$ withdrawal. However, thyroid failure was of a subclinical nature in the majority of the cases. It has also been shown that in those with postpartum overt hypothyroidism, nearly

Table 2 Time of recurrence of hypothyroidism and serum hormone concentrations following discontinuation of L-T 4 therapy in 172 patients with postpartum thyroiditis-induced hypothyroidism. Values are means \pm S.D.

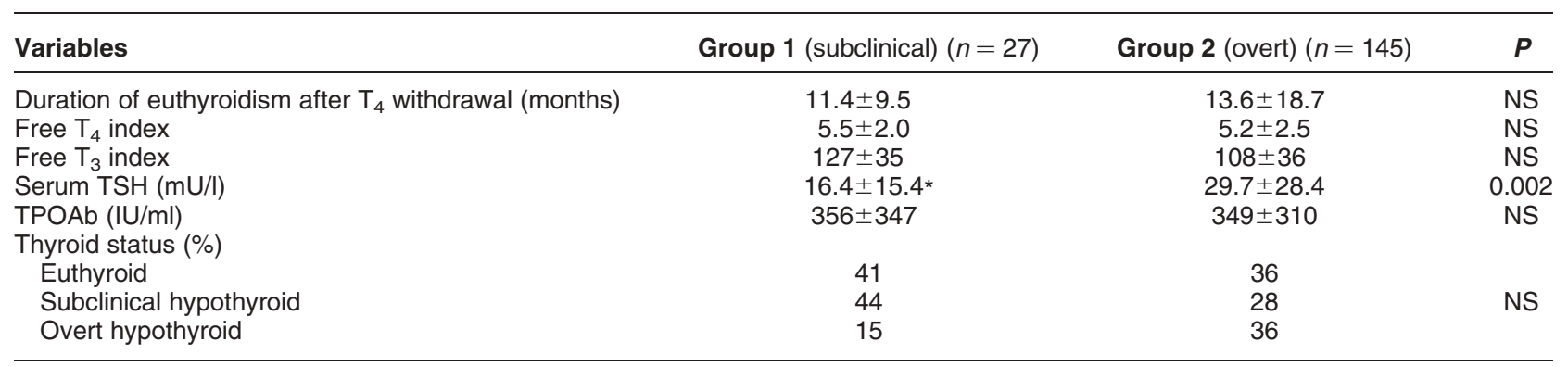

* Median (and ranges) of serum TSH for subclinical and overt postpartum thyroiditis subjects are: 11.0 (1.2-50) and 32 (0.5-100) mU// respectively. NS, not significant. 


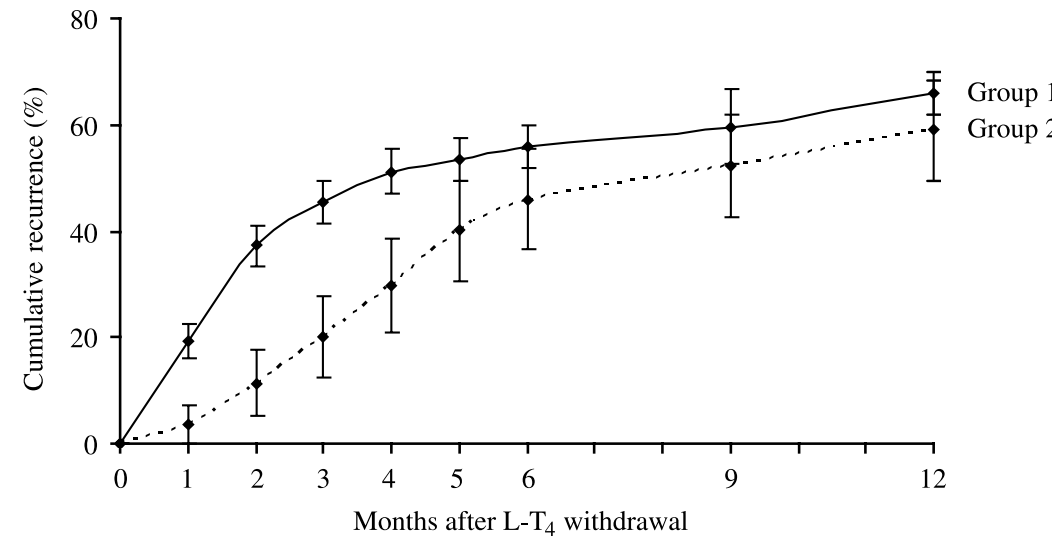

$\begin{array}{cccccccccc}\text { Group 1 } & \frac{0}{27} & \frac{1}{26} & \frac{2}{23} & \frac{2}{21} & \frac{2}{19} & \frac{2}{17} & \frac{1}{16} & \frac{1}{15} & \frac{1}{14} \\ \text { Group 2 } & \frac{0}{145} & \frac{28}{117} & \frac{21}{96} & \frac{8}{88} & \frac{5}{86} & \frac{2}{84} & \frac{2}{82} & \frac{3}{79} & \frac{5}{74}\end{array}$

Figure 1 Rates ( \pm S.E.M.) of recurrence of hypothyroidism in 172 of the original 213 patients with postpartum hypothyroidism who returned for follow-up after discontinuation of $\mathrm{T}_{4}$ therapy. The numerators are the number of patients with hypothyroidism during the previous interval, and the denominators are the number of subjects at the end of that interval. The difference between the two groups is statistically significant only at 2 months after L- $\mathrm{T}_{4}$ withdrawal. two-thirds developed recurrent thyroid failure with the majority being of the overt hypothyroid nature.

Six studies of long-term follow-up evaluations on women with PPTD have been conducted. The prevalence of recurrent or permanent hypothyroidism has been reported to be $12 \%$ in 27 subjects at the end of 3 years (5), 23\% in 44 subjects at a mean follow-up of 8.7 years (15), 23\% in 43 subjects at a mean follow-up of 3.5 years (14), 30\% in 47 subjects at the end of 5 years (16), $24.5 \%$ in 98 women at a median follow-up of 6.6 years (12) and 63\% in 148 women with severe PPTD (13). The current study represents the largest cohort of PPTD subjects followed after discontinuation of $\mathrm{T}_{4}$ treatment in the literature and the only study that has separated outcome in subclinical hypothyroid cases. The difference in prevalence of hypothyroidism in various studies may be due to the differences in the length of follow-up, criteria for diagnosis and, in particular, the severity of hypothyroidism in the original episode of PPTD.

Another important factor is the length of follow-up of patients with PPTD. We had shown that PPTD patients, who remained euthyroid after $\mathrm{T}_{4}$ withdrawal, had significantly higher values for TSH, as compared with the control group and $73.3 \%$ had TPOAb above the normal limit (15). This finding is in agreement with a previous report that euthyroid women with a previous history of PPTD have a permanent subtle defect in thyroid hormone synthesis, as evidenced by an abnormal iodine-perchlorate discharge test (18). Therefore, with longer follow-up, a good number of these patients may develop thyroid failure.

In the present study, there was no difference in TPOAb titers between patients with subclinical and overt hypothyroidism. Many investigators have found a relationship between PPTD and elevated levels of maternal serum TPOAb (19). It has been shown that at least $50 \%$ of TPOAb-positive women will eventually develop PPTD $(4,20)$. In addition, in a long follow-up $46 \%$ of TPOAb-positive and only $1.4 \%$ of TPOAb-negative women developed permanent hypothyroidism. The role of TPOAb in the development of postpartum thyroid dysfunction and the occurrence of permanent hypothyroidism is therefore well established. However, the findings of the present study point out that other factors, in addition to TPOAb, may determine the severity of thyroid damage and the probability of permanent hypothyroidism in patients with PPTD.

This study has a few limitations. First, all women with PPTD had a palpable goiter. This is unusual, although goiter is frequent in PPTD. Although Iran reached iodine sufficiency in 1995 (21), it is possible that the palpable goiters may have, to some extent, been caused by a previous iodine deficiency (22). Secondly, more than half of the patients were referred by gynecologists, pediatricians and internists, and the rest came directly to the endocrine clinic because of goiter or symptoms of thyroid dysfunction. This group of patients has therefore mostly been selected and does not represent the entire population of PPTD patients. Thirdly, one-fifth of the cohort was lost to follow-up and these may have been patients with less severe symptoms, indicating that the true prevalence of subclinical hypothyrodism may exceed that demonstrated by the present report.

In conclusion, this study has demonstrated that even the subclinical form of PPTD which presents only with an enlargement of the thyroid may proceed to permanent thyroid failure, both subclinical and overt, although in less severe forms than would the overt form of PPTD. Clinicians should carefully screen for diagnosis and long-term follow-up of patients with both subclinical and overt PPTD should be carried out. The above-mentioned finding calls for a comprehensive cost-beneficial investigation of screening for PPTD. The timely recognition of mild to severe cases 
of PPTD, their diagnosis and proper clinical management is important and improves the quality of life for both mothers and their infants.

\section{Acknowledgements}

The author would like to thank all participants, the staff of Research Laboratory of Endocrine Research Center, N Shiva for editing the English, M Padyab for statistical assistance and T Fakhimi for her help in preparing the manuscript. Funds were provided by the Endocrine Research Center.

\section{References}

1 Lazarus JH. Prediction of postpartum thyroiditis. European Journal of Endocrinology $199813912-13$.

2 Davies TF. The thyroid immunology of the postpartum period. Thyroid $19999675-684$.

3 Roti E \& Uberti E. Post-partum thyroiditis - a clinical update. European Journal of Endocrinology 2002146 275-279.

4 Amino N, Mori H, Iwatani Y, Tanizawa O, Kawashima M, Tsuge I, Ibaragi K, Kumahara Y \& Miyai K. High prevalence of transient postpartum thyrotoxicosis and hypothyroidism. New England Journal of Medicine 1982306 849-852.

5 Nikolai TF, Turney SL \& Roberts RC. Postpartum lymphocyte thyroiditis. Prevalence, clinical course, and long-term follow-up. Archives of Internal Medicine 1987147 221-224.

6 Freeman R, Rosen H \& Thysen B. Incidence of thyroid dysfunction in an unselected postpartum population. Archives of Internal Medicine $19861461361-1364$.

7 Lervange HH \& Pryds O. Ostergaard Kristensen HP. Thyroid dysfunction after delivery: incidence and clinical course. Acta Medica Scandinavica 1987222 369-374.

8 Roti E, Bianconi L, Gardini E, Minelli R, De Franco ML, Bacchi Modena A, Bresciani D, Villa P, Neri TM \& Savi M. Postpartum thyroid dysfunction in an Italian population residing in an area of mild iodine deficiency. Journal of Endocrinological Investigation $199114669-674$.

9 Walfish PG, Meyerson J, Provias JP, Vargas MT \& Papsin FR. Prevalence and characteristics of post-partum thyroid dysfunction: results of a survey from Toronto, Canada. Journal of Endocrinological Investigation 199215 265-272.

10 Barca MF, Knobel M, Tomimori E, Cardia MS \& Medeiros-Neto G. Prevalence and characteristics of postpartum thyroid dysfunction in Sao Paulo, Brazil. Clinical Endocrinology 200053 21-31.
11 Shahbazian HB, Sarvghadi F \& Azizi F. Prevalence and characteristics of postpartum thyroid dysfunction in Tehran. European Journal of Endocrinology 2001145 397-401.

12 Permawaradhana LD, Parkes AB, Ammari F, John R, Darke C, Adams H \& Lazarus JH. Postpartum thyroiditis and long-term thyroid status: prognostic influence of thyroid peroxides antibodies and ultrasound echogenicity. Journal of Clinical Endocrinology and Metabolism 200085 71-75.

13 Azizi F. Age as a predictor of recurrent hypothyroidism in patients with postpartum thyroid dysfunction. Journal of Endocrinological Investigation 200427 996-1002.

14 Othman S, Phillips DI, Parkes AB, Richards CJ, Harris B, Fung H, Darke C, John R, Hall R \& Lazarus JH. A long-tern follow-up of postpartum thyroiditis. Clinical Endocrinology 199032 559-564.

15 Tachi J, Amino N, Tamaki H, Aozasa M, Iwatani Y \& Miyai K. Long term follow-up and HLA association in patients with postpartum hypothyroidism. Journal of Clinical Endocrinology and Metabolism 198866 480-484.

16 Jansson R, Dahlberg PA \& Karlsson FA. Postpatrum thyroiditis. Bailliers Clinical Endocrinology and Metabolism 19882 619-635.

17 Assessment of the iodine deficiency and monitoring their elimination, a guide for programme manager. Report of Consultation, 46 May 1999. Geneva: WHO/UNICEF/ICCIDD, WHO/NHD, 01.1, 2001.

18 Roti E, Minelli R, Gardini E, Bianconi L, Neri T, Gavaruzzi G, Ugolotti G, Salvo D \& Braverman LE. Impaired intrathyroidal iodine organification and iodine-induced hypothyroidism in euthyroid women with a previous episode of postpartum thyroiditis. Journal of Clinical Endocrinology and Metabolism $1991 \mathbf{7 3}$ 958-963.

19 Amino N, Tada H, Hidaka Y, Crapo LM \& Stagnaro-Green A. Therapeutic controversy: screening for postpartum thyroiditis. Journal of Clinical Endocrinology and Metabolism $1999 \mathbf{8 4}$ 1813-1821.

20 Harris B, Othman S, Davies JA, Weppner GJ, Richards CJ, Newcombe RG, Lazarus JH, Parkes AB, Hall R \& Phillips DI. Association between postpartum thyroid dysfunction and thyroid antibodies and depression. British Medical Journal 1992305 $152-156$.

21 Azizi F, Sheikholeslam R, Hedayati M, Mirmiran P, Malekafzali H, Kimiagar M \& Pajouhi M. Sustainable control of iodine deficiency in Iran. Journal of Endocrinological Investigation $2002 \mathbf{2 5}$ 409-413.

22 Azizi F, Kimiagar M, Nafarabadi M \& Yassai M. Current status of iodine deficiency disorders in the Islamic Republic of Iran. Eastern Mediterranean Health Journal 19908 23-27.

Received 29 March 2005

Accepted 1 June 2005 